\title{
Endoscopic Ultrasonography Features of Colonic Muco-Submucosal Elongated Polyp
}

M. Takahashi, M. Kubokawa, M. Tanaka, Y. Sadamoto, K. Ito, R. Yoshimura,

N. Harada, H. Nawata

Department of Medicine

and Bioregulatory Science,

Graduate School of Medical Sciences, Kyushu University, Fukuoka, Japan

\section{Reference}

${ }^{1}$ Matake $\mathrm{H}$, Matsui T, Yao T et al. Long pedunculated colonic polyp composed of mucosa and submucosa. Proposal of a new entity, colonic muco-submucosal elongated polyp. Dis Colon Rectum 1998; 41: $1557-1561$

\section{Corresponding Author}

\section{N. Harada, M.D.}

Department of Medicine and Bioregulatory Science

Graduate School of Medical Sciences Kyushu University

Maidashi 3-1-1

Higashi-ku

Fukuoka 812-8582

Japan

Fax: $\quad+81-92-6425287$

E-mail: zico@intmed3.med. kyushu-u.ac.jp

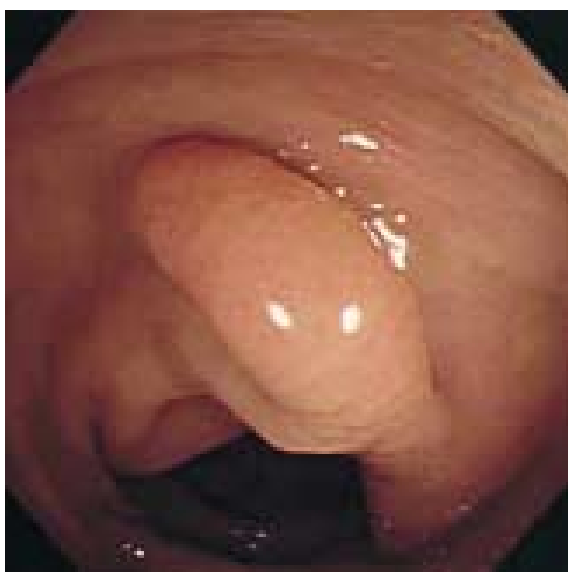

Figure 1 A 52-year-old man presented at our hospital with continuous back pain. Colonoscopy revealed a small polyp $1 \mathrm{~cm}$ in length in the transverse colon. Its surface was smooth and covered with normal colonic mucosa

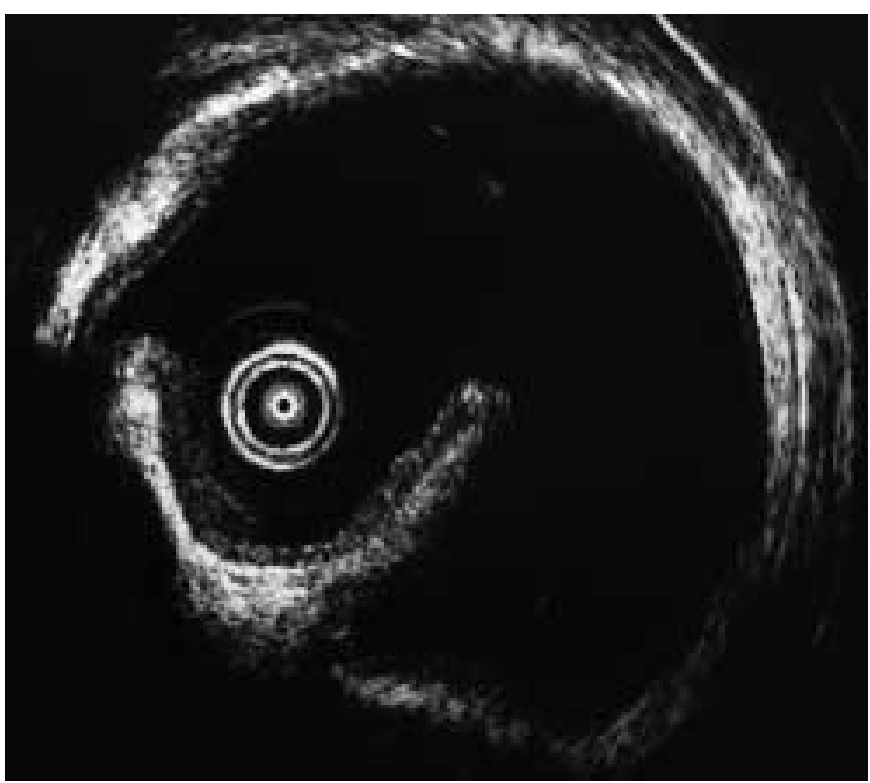

Figure 2 Endoscopic ultrasonography (EUS) demonstrated an elongation of the first to third layers, revealing mucosal and submucosal colonic layers. The layer structure was intact, and there were no gross lesions in the polyp. The features were compatible with colonic muco-submucosal elongated polyp (CMSEP), which was first reported by Matake et al. [1]. The resected specimen revealed a polyp with a smooth surface and covered with normal colonic mucosa, representative of CMSEP. We suggest that, from now on, a small polyp diagnosed as a CMSEP by EUS could be followed up without polypectomy 